\title{
O Psíquico e o Corporal da Sexualidade nas Origens da Psicanálise Freudiana
}

\author{
Luiz Augusto M. Celes ${ }^{1, *}$ (D) \& Cristina Lindenmeyer, ${ }^{2, * *}$ (D) \\ ${ }^{1}$ Universidade de Brasília, Brasília, DF, Brasil \\ ${ }^{2}$ Université Paris Diderot-Université de Paris, Paris, France
}

\begin{abstract}
RESUMO - O artigo tem por objetivo explorar, em uma perspectiva teórica conceitual, a presença corporal da sexualidade na compreensão da psicanálise, não se esgotando ela no psiquismo. Argumenta-se que as vivências primitivas da sexualidade (a sexualidade infantil) não somente determinam formas da fantasia e dos sintomas, mas vigem como vivências corporais de estímulo e excitação, satisfação, prazer de órgão e dor. Para isso, percorre-se os diversos modos da presença da sexualidade nas neuroses e nas perversões, tais como compreendidas a partir dos primeiros textos de Freud, mostrando suas raízes no corpo e seus traços originários como permanentemente corporais. Conclui-se com a irredutibilidade entre psiquismo, sexualidade e corpo.
\end{abstract}

PALAVRAS-CHAVE: neurose, perversão, dor-prazer, representação, afeto, pulsão

\section{The Psychic and the Corporal of Sexuality in the Origins of Freudian Psychoanalysis}

\begin{abstract}
The article aims to explore, from a conceptual and theoretical perspective, the corporeal presence of sexuality in the comprehension of psychoanalysis, not exhausting it in the psyche. It is argued that the primitive experiences of sexuality (infantile sexuality) not only determine forms of fantasy and symptoms, but also act as bodily experiences of stimulation and arousal, organ satisfaction and pleasure and pain. In order to do so, one goes through the various modes of the presence of sexuality in neuroses and perversions, as understood from Freud's early texts, showing their roots in the body and their original features as permanently bodily. It is concluded with irreducibility between psyche, sexuality and body.
\end{abstract}

KEYWORDS: neurosis, perversion, pain-pleasure, affect, pulsion

No Caso Dora, Freud (1905/1989a) assinala que retorna às suas preocupações com a neurose (precisamente nesse caso) após um período dedicado à apreensão do psiquismo (uma teoria do psiquismo), alcançada em $A$ interpretação dos sonhos (Freud, 1900/1987). O caso Dora se situa no lugar de uma síntese em que convergiriam a teoria do inconsciente, o processo de interpretação de sonhos e o tratamento da neurose. Estranhamente, no que diz respeito à presença da sexualidade no tratamento, Freud parece não ter muito o que oferecer ao leitor, pelo que exige dele crença no papel e função da sexualidade na constituição da histeria e em seu tratamento. $\mathrm{O}$ fato da incompletude da teoria da sexualidade se mostrar em sua primeira abordagem na forma de ensaios (Freud, 1905/1989b) parece reafirmar a preocupação freudiana com a compreensão do leitor.

Além da ruptura de percurso e suposto retorno apontados por Freud (neurose - sonhos - neurose), constata-se certo hiato entre a teoria do psiquismo, explorada e construída ao modo de uma investigação científica, isto é, para o conhecimento do inconsciente, em $A$ interpretação dos sonhos, e a teoria da sexualidade, muito mais construída como resultado de certo apanhado na fala das histéricas tratadas por Freud. A preocupação de Freud em construir uma síntese desse apanhado, aparece expressa em sua carta

\footnotetext{
*E-mail: lamceles@gmail.com

** E-mail: cristina.lindenmeyer@wanadoo.fr

n Submetido: 15/10/2019; Revisado: 21/01/2020; Aceito: 21/03/2020.
} 
a Fliess, na qual se queixa de que lhe escapa uma centelha que o ilumine nesse sentido (Carta a Fliess de 26/01/1900, in Masson, 1986, p. 397-398). Essas vicissitudes com rupturas, desvios e ensaios mostram que o desenvolvimento de constituição da psicanálise não foi um caminho linear, homogêneo e progressivo em direção à conquista do psiquismo nem se buscou somente um conhecimento do psíquico. Também a psicanálise se preocupou com a resistente sexualidade e com os aspectos orgânicos corporais nela implicados, como nos propomos discutir.

Os textos freudianos de 1905, como os citados, atualizam questões que se impunham já no período anterior a $A$ interpretação dos sonhos (Freud 1900/1987), revelando uma sexualidade ainda não completamente incluída nas considerações metapsicológicas. O Caso Dora, por um lado, e os Três ensaios sobre a teoria da sexualidade (Freud $1905 / 1989$ b), por outro, trazem à baila novamente um resto insolúvel da análise - que não se justifica completamente na falta de investigação do inconsciente - e mostram a crueza e a efetividade da sexualidade, apesar do psiquismo, contidas na compreensão da perversão. O resto que escapa à análise e à compreensão da sexualidade parece ser o corpo em seu sentido pulsante. $\mathrm{O}$ aspecto que vamos aqui salientar, de um modo mais geral e menos específico, diz respeito ao forte entrelaçamento entre o psíquico e o corporal, "mediados" pela sexualidade, sem que se esgotem um no outro. A relativa independência do psíquico e do corporal em análise já se manifestam nos textos iniciais de Freud e pode ser apreendida pelas considerações com a sexualidade.

\section{A CONSTRUÇÃO DA SEXUALIDADE COMO SEXUALIDADE CORPORAL - ALGUMAS INDICAÇÕES DA SEXUALIDADE CORPORAL NA NEUROSE}

A insolubilidade expressa no Caso Dora — não a do caso propriamente, que é singular e tem seus determinantes particulares, mas o que é exemplar no caso Dora - situa-se além do objetivo freudiano de justificar a aplicabilidade da interpretação de sonhos à análise. Afora esse objetivo, encontramos a questão da sexualidade que se impõe por outra via. Freud (1905/1989a) se diz convicto do papel da sexualidade na constituição da neurose, porém incerto quanto a uma teoria da sexualidade e, em consequência, quanto aos recursos que teria para convencer seus leitores da importância do fator da sexualidade e a exigência de crença que faz ao leitor. Não nos parece despropositado supor que Freud lança o leitor para a apreensão da sexualidade na fala da analisanda Dora, antes de ser suficientemente teorizada. (Celes, 1995)

É pelo acolhimento da narrativa da paciente que o caso apresenta muito do que será posteriormente uma teoria da sexualidade (sempre incompleta); muito dos achados do modo característico da sexualidade humana e de sua vivência, associada, mas não de maneira uniforme e permanente, à fantasia. O caso apresenta facetas da sexualidade infantil, utiliza-se de noções da teoria da sexualidade - por exemplo, zona erógena -, mostra como a atividade sexual infantil constitui-se base dos sintomas - fixação, complacência somática - e revela a fantasia edípica que se utiliza do corpo para a formação do sintoma histérico.

Sustentam-se no caso as ideias da efetividade histórica das experiências sexuais infantis: Dora ainda pequena tinha o hábito de chupar o dedo, constituindo-se aí a base somática de sua oralidade; as cenas de sedução rememoradas não são colocadas em xeque quanto à sua vivência factual, atualizando as queixas edípicas de Dora e muitos de seus sintomas, etc. A fantasia, que é da esfera do psiquismo e que, por isso, se deixa interpretar, vincula-se às condições corporais estabelecidas pelas experiências sexuais. $\mathrm{O}$ traço permanente e insistente da vivência sexual infantil que se fixou colabora para a formação do sintoma, e com isso, permite a regressão da sexualidade genital para uma condição infantil. No caso, a satisfação oral fartamente vivenciada na infância de Dora serve de apoio ao deslocamento da excitação sexual genital para a constituição do sintoma da tosse, por exemplo. Tal sintoma, na interpretação, revela-se como atualização da fantasia edípica de Dora.

Neste sentido, pode-se compreender que a importância dada à fantasia anunciada na carta à Fliess de 21/09/1897 (in Masson 1986, p. 265-267), cuja ênfase na fantasia conduziu ao abandono da neurótica, não deve levar ao entendimento de que ela, a fantasia, reina de maneira absoluta no psiquismo. O entendimento freudiano, diversamente do que se poderia esperar com a afirmação da prevalência da fantasia, apoia-se na vivência efetiva da sexualidade - como no prazer oral de Dora, que também parece ser a base corporal da complacência somática na constituição do sintoma (Freud, 1905/1989a). Por similaridade, pode-se dizer que a neurótica, isto é, o trauma - a efetividade do trauma - deixa traços, como traços de memória, como "representação de coisas" na teoria da constituição e organização do psiquismo que se constrói a partir de Dora.

A decifração do inconsciente, tarefa que foi tão amplamente e profundamente estabelecida em $A$ interpretação dos sonhos, mostra seu limite no tratamento da neurose. E o limite será a efetividade corporal da vivência sexual infantil. 


\section{ALGUMAS INDICAÇÕES DA PRESENÇA CORPORAL NA PERVERSÃo}

Três ensaios de teoria da sexualidade (Freud, 10905/1989b) reafirma o caráter da sexualidade que não se confunde completamente com a fantasia. "O livro sobre a perversão" como poderíamos designá-lo, parafraseando a expressão freudiana "o livro sobre o sonho" - referindose a A Interpretação dos sonhos (in Masson 1986, p. 267) —, encontra sua razão de ser além das fantasias sexuais inconscientes. O primeiro ensaio, versando justamente sobre a perversão, do qual modelo Freud elucidará a sexualidade infantil e, em seguida, suas transformações, traz todo o peso de uma sexualidade efetivamente vivida para a compreensão de suas características, mais precisamente dizendo, para a sua conceituação na psicanálise. No livro referido, a perversão não é usada como uma metáfora para uma aproximação à sexualidade infantil, mas é, mais apropriadamente dizendo, o modelo da sexualidade. A perversão tende mais para a compreensão de uma concretização corporal da sexualidade do que para sua simbolização.

No entanto, a afirmação de que a histeria é o negativo da perversão conduz a uma dupla e, aparentemente contraditória, compreensão: a de uma certa ausência da fantasia na perversão - e por suposto na sexualidade infantil enquanto definição da sexualidade - e a da possibilidade de se encontrar na análise da fantasia do histérico as características infantis da sexualidade perversa - portanto, sua natureza de fantasia.

Encontramos na obra freudiana pelo menos três formas da perversão, que curiosamente não se excluem nem se completam de maneira linear, quais seriam: (a) a perversão entendida como manutenção e continuidade das experiências infantis de prazer - extensão direta da sexualidade infantil - (Freud, 1905/1989b); (b) a que se define pelo fetichismo, portanto pela intermediação do trabalho psíquico para a sua constituição e para a realização do prazer (Freud, 1927/1988a), e (c) a perversão que é o masoquismo primário, forma esta da perversão para cujo entendimento se torna necessária a consideração da pulsão de morte (Freud, 1924/1989c). A primeira e a terceira das formas do entendimento da perversão revelam a sexualidade em suas características primitivas - formas fortemente ligadas às teorias pulsionais de Freud - , enquanto a segunda, mostra a sexualidade perversa já organizada segundo um trabalho psíquico de defesa contra a castração — trabalho do narcisismo - ela seria, por assim dizer, uma forma secundária de perversão. Como nos interessa aqui mostrar aspectos além do psíquico, a segundo será objeto de discussão de menor atenção.

Nos Três ensaios, a perversão é a que advém diretamente, por assim dizer, da vivência infantil da sexualidade (perversa-polimorfa por definição). Seria ela entendida como a continuidade (da criança ao adulto) da experiência de prazer infantil sem os obstáculos ou os desvios impostos pelo psiquismo. Tal concepção seria como a da busca de um suposto prazer-puro, que não se submeteu às defesas psíquicas. Talvez possamos encontrar aí o modelo freudiano do "eu-prazer purificado" (Freud, 1915/1989d, p. 131). Tratar-se-ia da compreensão da perversão como se fosse a invasão do psiquismo e do corpo pela exigência da descarga da excitação de órgão sem mediações propriamente ditas, como num curto-circuito entre a excitação e a descarga pulsional - sabemos, o modelo freudiano é o arco-reflexo. O princípio do prazer se imporia apesar dos obstáculos, sejam os psíquicos, sejam os da realidade etc. A sanha do prazer expressa de modo adequado tal perversão que, como tal, reafirma o concretismo ou a efetividade da sexualidade perversa e, por consequência, da vivência sexual infantil de prazer, prazer de órgão, justamente. Ao cabo e ao fim, podemos entender que se lida, no caso, com uma sexualidade não simbolizada, seja porque dispensa os obstáculos e os limites ao prazer, seja porque ela parece não ser fruto de sínteses, de amalgamentos em sua constituição final. Isso sugere o estado da vivência sexual infantil precariamente simbolizada, muito mais sensorial, encarnada, como se a representação da coisa (traços de memória da vivência de prazer) imperasse, impondo seu circuito, de tal modo que o alucinatório e a vivência efetiva do prazer se confundiriam. A ativação dos traços de memória da vivência primitiva de satisfação, o alucinatório primitivo, nos permitimos dizer, está mais próximo do sensório-corporal do que da fantasia afinal elaborada ou sintetizada como cena de satisfação. A perversão se torna o modelo de uma sexualidade principalmente pulsional-corporal, tornando o trabalho psíquico secundário na busca de satisfação.

O segundo modo da compreensão da perversão (o fetichismo), no que pese a presença do psiquismo para a sua constituição - restos (representações?) imobilizados e psiquicamente isolados da percepção da castração — conduz à compreensão de uma forma de defesa (a recusa) que por si só coloca em cheque o domínio da fantasia, mesmo que se mantenha o entendimento da base fantasmática inconsciente de toda organização subjetiva, como o sugere Aulangnier-Spairani (2003). A recusa não visa em seu primeiro momento o juízo (o pensamento), mas a percepção - recusa da percepção da castração na mãe. Trata-se da dificuldade de acolhimento do traço de percepção pelo psiquismo, dificuldade de integração da percepção e suas consequências no psiquismo. A percepção da castração no outro contraria, como que por assim dizer, todo o sistema de fantasias narcísicas constituído pelo trabalho psíquico para dar conta do estímulo pulsional nas relações do sujeito com seus outros primitivos. Podemos afirmar que se encontra presente um trabalho psíquico que age sobre as funções do corpo, do organismo, no caso a função perceptiva. E não se trata - caso contrário não valeria o esforço de entendimento do fetichismo - de outra compreensão de uma "cegueira" sintomática. A recusa da percepção traz consequências 
psíquicas graves - a cisão do Eu. A impossibilidade do $\mathrm{Eu}$ decidir-se diante dos juízos opostos - aquiescência e não-aquiescência da castração percebida e recusada impõe um trabalho extra de defesa, evitando a perda total de si mesmo na psicose, cuja consequência é a cisão do $\mathrm{Eu}$ pelo inconciliável da situação. Que a cisão se faça sobre o $\mathrm{Eu}$, desperta-nos a curiosidade de um trabalho psíquico inconsciente, por certo - cujo efeito se opera sobre o quê, por princípio, seria a instância responsável pela manutenção da realidade para o sujeito. A partir daí, o prazer se alcança somente mediado pelo fetiche, que não se reduz a uma fantasia. $O$ fetiche é resultado da negatividade da presença substituída pela positividade da presença de um objeto, imutável, o que só pode se sustentar na fissura no Eu. O fetichismo não é simplesmente o sintoma de um desejo de fantasia em conflito com o Eu. Sustenta-se a sexualidade fetichista, mutuamente, na interferência psíquica sobre o corpo e o inverso.

No modo primário da perversão, o masoquismo, o que se impõe além do prazer é a dor, como observou claramente Freud (1924/1989c). Um amalgamento primitivo entre a dor e o prazer condiciona a satisfação sexual. A dor da qual se constitui o masoquismo (certamente não somente o masoquismo) se confunde com a própria excitação sexual, excitação provocada pela pulsão. Como se sabe, a pulsão se origina no órgão, que precisa ser especificamente estimulado para sua cessação como prazer. A aproximação entre prazer e dor, no entanto, é primária, na medida em que o estímulo de órgão é ele mesmo prazeroso (tal como acontece nas estimulações preliminares ao ato sexual). A sexualidade então se destina nas diversas formas do masoquismo (erógeno, feminino e moral) tendo por base a dor, que não é outra coisa que dor do corpo, "dor de órgão", podemos sugerir escrever em paralelo a "prazer de órgão". Embora o masoquismo moral, por exemplo, possa estar fenomenologicamente muito distante da apreensão da dor que lhe dá origem, a organização masoquista está, não obstante, inteiramente apoiada na dor primitiva, se é que podemos designar assim. E não raro se transforma (se desloca?) é vivida como dor psíquica. Particularmente em algumas configurações obsessivas, uma dor psíquica se impõe como queixa do sujeito da análise.

Apesar de nos restringirmos aqui à dor vincula ao masoquismo, ela já se encontra na origem da constituição do psiquismo, tal como Freud (1950/1988b) a aborda no Projeto para uma psicologia científica. Também se pode considerar, acompanhando Delouya (2001), que a dor seja responsável pela instauração de corpo e psiquismo. A dor, provocada pelo excesso de tensão interna ou externa ao organismo, exige trabalho psíquico para sua descarga, no mesmo passo, a percepção do órgão dolorido o delimita, permitindo, por assim dizer, seu contorno, que será o contorno do corpo, inicialmente em seu estado parcial. Como o sugere o exemplo de Freud, o molar dolorido convoca todo o narcisismo e, nesse momento, o molar é parcial e é corpo inteiro... Para Aulagnier (1994), “A « coisa » corporal se impõe neste caso [da dor, do sofrimento] como antinômica com respeito a um corpo pensado como corpo-prazer" (p. 136). A ideia é que, particularmente na dor, o corpo se apresenta como independente do psiquismo, ele escapa ao Eu pensante, nos termos que aqui usamos, está além da simbolização e da significação. A única significação possível será a de que o corpo escapa ao psiquismo, assim, talvez seja excessivo concluir, mas pode-se entender que a dor delimita o psíquico na sua diferenciação como não-psíquico. No entanto, a dor e sua função de constituição do psiquismo e do corpo merecem certamente longa abordagem que não será aqui realizada.

O masoquismo primário se encontra além do princípio do prazer. Impera aí a satisfação pulsional a mais direta possível, a tendência ao zero que se sobrepuja ao prazer. Uma espécie de prazer máximo sem as ressalvas da oposição prazer-desprazer. Isso, se considerarmos a pulsão de morte como tal. No entanto, o masoquismo já parece ser uma forma mesclada das pulsões de vida e de morte, cuja consequência seria justamente o masoquismo em sua duplicidade dorprazer. Vamos desenvolver um pouco essa proposição.

Tomando dos Três ensaios a consideração básica de que a sexualidade é infantil, perversa-polimorfa, sendo essa a base de qualquer de seus destinos, o que se poderia adiantar se se traz tal fundamento para pensar os destinos da sexualidade a partir do masoquismo primário? Seria necessário então supor a presença do masoquismo na fonte de toda sexualidade. Mais ainda, podemos entender que toda sexualidade em sua origem está marcada pela dor, tomada em seguida pelo prazer. Assim dito, podemos sugerir o apoio da sexualidade na dor-corporal - quer dizer, a dor que não é a dor psíquica. Aproximamo-nos do entendimento freudiano do apoio para a compreensão da origem da sexualidade e da repetição da via pulsional de busca do prazer. No entanto, certa coerência de tal raciocínio, a nós nos parece que o masoquismo primário evoca uma condição mais primitiva do que as clássicas formas das organizações sexuais infantis. As organizações da sexualidade infantil parciais (oral, sádico-anal, fálica) têm desenvolvimento independente (característica de sua parcialidade, justamente) e se constituem, pelas fixações das vivências repetidas de prazer, as bases, melhor dizendo, as matrizes da vida sexual do sujeito. $\mathrm{O}$ apoio parece então se distribuir segundo zonas erógenas distintas. Se queremos manter a ideia do apoio para a compreensão da associação entre dor e prazer no masoquismo, ele terá de receber uma generalização que transcende a zonas erógenas específicas. O que queremos mostrar é que a dor que também é origem do masoquismo primário está situada como fundamento essencial da tensão que dá origem ao movimento pulsional no sentido de sua descarga. $\mathrm{O}$ aumento de tensão considerado como desprazer que conduz ao trabalho da descarga, do que resulta o prazer - segundo uma das oposições vitais introduzidas por Freud (1915/1989d), no caso, a do prazerdesprazer -, repetindo, o mesmo aumento de tensão no 
corpo, no órgão fonte da pulsão, seria ele a origem da dor. O aumento de tensão não é somente desprazeroso, é dolorido. O masoquismo, nesta linha de pensamento, seria a tentativa de assimilação da dor ao prazer.

Nas três formas da perversão - que caracterizam a sexualidade infantil como tal — constata-se a não dominação do psiquismo de modo completo. Resta o corpo e seus órgãos em suas funções mais primitivas (em certo sentido à serviço da autoconservação, mas não somente). $\mathrm{O}$ corpo dor-prazer, vinculado à característica pulsional e à condição de excitação do corpo (dos órgãos), impõe trabalho ao psiquismo (como já anunciada na definição de pulsão), mas este, o trabalho psíquico, não o domina completamente. O corpo é permanentemente excitado, mesmo quando repousa. A cessação completa dos estímulos corporais é a realização sem desvio da pulsão de morte. Para se haver com as excitações, mas também com sua falta ou a ameaça de sua falta completa, corpo e psiquismo trabalham. O corpo está novamente além psíquico, é o que o "lembra" da vulnerabilidade do $\mathrm{Eu}$, de condição para a morte, propriamente.

\section{RETOMANDO A LIÇÃO DA NEUROSE}

A interpretação dos sintomas também revela dois aspectos da sexualidade: as fantasias inconscientes recalcadas - verdadeiras cenas de sedução — , bem como os traços das vivências sexuais infantis em sua forma fixada. A decomposição (análise) da sexualidade perversa como traços fixados da experiência vivida e simultaneamente amalgamada pelos estágios posteriores do desenvolvimento da sexualidade (a sexualidade genital), na qual se inclui a fantasia, também se alcança com a análise do sintoma histérico. Nesse aspecto, o caso Dora continua exemplar. (Lindenmeyer, 2019)

A fantasia de felação interpretada por Freud (1905/1989a) no sintoma de rouquidão e tosse de Dora torna presente simultaneamente a oralidade fixada - fixação esta que se dá pelo excesso da ativação do prazer de chuchar de Dora - e a genitalidade advinda e corrente em Dora adulta. O processo psíquico implicado na perversão se mostra então pelo seu avesso no sintoma, como sendo o trabalho no qual a sexualidade infantil fixada se desloca pela via da satisfação genital. No caso indicado, esta última encontra sua satisfação na oralidade. Então, diferentemente do que seria o destino idealmente esperado do desenvolvimento da sexualidade, no qual a genitalidade seria ponto de síntese (sempre incompleta) da sexualidade infantil parcial, na perversão, esta última, qual seja, uma organização (termo exagerado para o caso) sexual infantil de satisfação determina os destinos da sexualidade genital. A síntese esperada da genitalidade, nessa primeira aproximação freudiana do desenvolvimento da sexualidade, falha, ficando ela transferida para o infantil fixado. No exemplo de Dora, a satisfação sexual se organiza em torno da oralidade, que se encena no sintoma da tosse.

Para a constituição da fantasia de felação, cuja matriz é a sexualidade oral fixada, é necessário, afirma Freud (1905/1989a, p. 47), que Dora conheça o "objeto sexual propriamente dito", no caso, o pênis, suposto objeto sexual genial da analisanda. Além do aspecto de desenvolvimento da sexualidade (da oralidade à genitalidade) implicado nessa afirmação, há que se perceber que Freud está falando de um objeto da satisfação sexual oral de Dora. O objeto, o pênis do sr. K., cuja ausência aciona o sintoma da rouquidão e tosse, diz dos efeitos da presença e ausência do outro que se ama, do objeto do amor de Dora, ao mesmo tempo, o sr. K. e o seu pênis (isto é, objeto total e objeto parcial). O sintoma da pressão no peito encena o agora perdido abraço do sr. K.: a pressão de seu pênis em seu (de Dora) ventre, e sua coexcitação; sendo o sintoma então estabelecido pelo mecanismo de deslocamento de baixo para cima, etc. Simultaneamente presentificam-se a genitalidade do outro e a própria de Dora.

A fantasia de felação é filha da fantasia edípica transferida para o sr. K. e do processo psíquico-corporal do deslocamento de baixo para cima - deslocamento da pressão sentida efetivamente no corpo, pelo menos é esta a interpretação de Freud (1905/1989a). Portanto, além da complacência somática implicada na oralidade sintomática, encontra-se um processo efetivamente psíquico-corporal do deslocamento aí atuante na formação do sintoma e da fantasia que ele (o sintoma) coloca em cena.

Não estamos ignorando que se trata de um corpo submetido à fantasia, de um corpo significante. Somente apontamos o que parece ficar à sombra ou é negligenciado na prática cotidiana da psicanálise, que não é infrequente prática. Marcamos o que Kristeva (2000) aponta como um déficit entre as representações sexuais e a palavra. O limite da palavra para a apreensão do sujeito se faz importante diante da proeminência das considerações quanto ao psiquismo (ou à fantasia), que deixa escapar a concretude da excitação e do corpo até mesmo na formação dos sintomas (realização da cena de fantasia). Embora essa concretude esteja amplamente tomada pela fantasia, também se denota que, ao inverso, o corpo e suas excitações se utilizam do trabalho psíquico para renovar suas vivências e marcas próprias. A excitação de órgão que é a origem do trabalho psíquico, é a exigência desse trabalho, está também no fim do trabalho - no prazer de órgão, tanto na perversão como no sintoma que apela diretamente ao corpo e suas excitações para sua constituição. 


\section{A SEXUALIDADE E O PRAZER}

A sexualidade carrega o sentido pulsional, pois implica a noção de aumento de tensão e da exigência de descarga. A vivência sexual se caracteriza, portanto, como excitação e prazer. Ambos possuem características orgânicas. A excitação é corporalmente vivenciada - mesmo quando se transforma em afeto de angústia - e o prazer é por definição prazer de órgão. $O$ psiquismo se encontra entre a fonte e o objetivo da pulsão. A pressão ou força que marca o aumento da excitação é capturada pelo psiquismo - precisamente pela imaturidade orgânica de solucionar a excitação - na forma de afeto e investimentos das representações, que são inconscientes, representações de coisas, representações de palavras e, no fim da linha, representações de objetos. Como observa Green (2000), o objeto faz parte integrante da cadeira de satisfação da pulsão de vida. E se para pensar tal cadeia de satisfação imaginamos, inspirados em Freud, uma linha progressiva rumo ao objeto, o ensaio do mesmo Freud de 1915 mostra as diversas formas de destinos pulsionais, incluindo algumas de regressão ao próprio corpo, nem sempre terminando no prazer. E aprendemos além Freud, que o objeto tem sua importância qualitativa e ele se encontra mesmo na origem da formação da cadeia de satisfação de Eros. Mas não vamos nos estender neste aspecto do objeto neste momento, embora alguma referência se faça a seguir.

O psíquico é principalmente mediador entre a tensão e a descarga. Assim, ele é também constituído no trajeto pulsional, tal como se afigura na vivência de uma primeira e suposta satisfação (primeira mamada teórica, como o designa Winnicott, 1945/1978). Pelo fato da imaturidade orgânica e psíquica (o psiquismo está justamente se constituindo como trabalho para dar destino à pulsão, aliás, trata-se de movimento sem fim quando não se cristaliza, se fixa - é a regra - em meios repetitivos de encaminhamento da pulsão), o psiquismo se integra no trajeto pulsional — na "cadeia de Eros" (Green, 2000) —, porque se constitui mediação do trajeto pulsional e dele se torna mediador. E se a estrutura permanecer neurótica, no sentido genérico, o psiquismo, também ele, pode se constituir objeto da pulsão, como o objeto de desejo da fantasia; também o corpo próprio pode se constituir objeto da pulsão, como no narcisismo, na hipocondria, etc... Assim, o psiquismo se afigura como essencial, indispensável e, por fim, tende a certa autonomia em relação ao corpo e ao mundo externo (objeto). Também lembramos como acima discutido, que a perversão sugere a autonomia do corpo em relação ao psiquismo na busca da satisfação. Corpo e psiquismo parecem gozar de relativa autonomia um em relação ao outro.

A crítica de Fairbairn (1952/1980), que entende o modelo freudiano como sendo o psiquismo uma máquina que é externamente energizada, não parece que se sustenta no caso, porque ele mesmo, o psiquismo, é constituído e não somente em seu processo de defesa contra o objeto frustrante ou excitante. Também a saída que propõe de uma estrutura psíquica ela mesma dinâmica, tem o mérito de incluir o objeto na constituição subjetiva, mas excluir o corpo, este, cujo sujeito dele não se destitui. $\mathrm{O}$ caso de um psiquismo dinâmico se assemelha, como entendemos, ao psiquismo já constituído como o do neurótico, por exemplo, ou a própria estrutura esquizoide de Fairbairn, mas já constituída, fixada...

O que sugerimos em nossa interpretação, é que se trata, na proposta freudiana, de um "aparelho" - a bem da verdade profundamente complexo e processador, isto é, um aparelho de trabalha - que é construído pelo próprio processo de mediação e descarga. Nesse sentido, mantemos uma compreensão paradoxal que entendemos ser própria do pensamento psicanalítico originado em Freud, qual seja, a simultaneidade do corpo e do psiquismo e seu entrelaçamento necessário e inescapável. A noção de corpo vivido e de carne (Vergote, 1970) permite compreender que o corpo é simultaneamente físico e simbólico. É carne, o que o qualifica de vivacidade e excitação: o corpo é espírito encarnado. Espírito, este no sentido usado por Freud ânima, pneuma -, isto é, psíquico. Então formulamos que o corpo é psiquismo encarnado. Mas também, para manter a complexidade e paridade da formulação freudiana, o psiquismo é corpo projetado. A designação de "aparelho" para o psiquismo (aparelho psíquico), como se diz dos aparelhos corporais (aparelho digestivo - para nos mantermos no exemplo da oralidade), seria um exercício freudiano de metabiologia (Green 2000), que, entendemos, metaforiza a dependência relativa e mútua entre psiquismo e corpo.

Desta maneira, estamos privilegiando ou simplesmente reconhecendo o corpo nos processos de subjetivação. Completando, mas não finalizando, sugerimos que a expressão realidade psíquica seja compreendida como a realidade mais ampla, envolvendo os aspectos da fantasia, do organismo, da realidade dita material e da realidade histórico e social. Podemos fazer nossas as palavras de Birman:

Isto nos conduz muito além de considerar que o psiquismo e o sujeito se fundam apenas na ordem simbólica e no registro da linguagem, pois esta leitura da subjetividade esquece que o psiquismo se inscreve em um corpo erógeno e pulsional para se constituir enquanto tal, não existindo então qualquer psiquismo que seja desencorpado. (Birman, 1996, p. 133)

Convém desfazer, então, o possível mal-entendido de que substituímos um dualismo corpo-psiquismo (tensão e fantasia) por um monismo integrado regido por um princípio único. Diferentemente, reafirmamos o paradoxo do pensamento psicanalítico a partir de Freud, onde corpo e psiquismo se articulam na busca jamais alcançável de uma síntese. Conhecemos, pela teoria da sexualidade, as figuras de sínteses em Freud, que seriam, em duas palavras, 
genitalidade e narcisismo. Mas também conhecemos as figuras disjuntivas, tais como, parcialidade, castração, zonas erógenas, fixação, pulsão sexual, pulsão de Eu, id e Eu e, finalmente, mas não tudo, pulsão de vida e pulsão de morte. Se por definição Eros se caracteriza pela integração e síntese, a pulsão de morte se a compreende pela força de desintegração, pela destrutividade, pelo desfazimento dos vínculos com os objetos da satisfação, pela entropia, pela deserotização no narcisismo, pelo "ataque" às fantasias e ao corpo, como no masoquismo primário acima discutido.

\section{SEXUALIDADE E INCONSCIENTE}

Se o psíquico pode ser entendido como o mediador do impulso sexual (este último apreendido pelo psiquismo como afeto) e sua satisfação, ele termina por ser um efeito secundário do processo de satisfação pulsional. Assim, o afeto pode ser pensado em sua independência com respeito às representações. E no tratamento psicanalítico, supõe-se a possibilidade da vinculação mais ou menos estável do afeto com as representações, de modo a que não se o tenha completamente livre (processo primário) a se manifestar como angústia, e que, por oposto, não se o tenha fixado demasiadamente forte a representações específicas, como se dá na formação do sintoma. As possibilidades de vinculações e desvinculações entre afeto e representações é campo conhecido da psicanálise - o que não quer dizer que se constitua como um problema de fácil resolução.

Certamente, o alcance da tarefa analítica de vincular as representações às excitações e aos prazeres não parece se desvelar em seu modo próprio. O corpo inerte do sujeito em análise sugere, aliás, certa reserva no tratamento das manifestações corporais as mais primitivas. Sugere também a tentativa de impedir o desenvolvimento, em análise, do circuito excitação-prazer (ou mesmo dor-prazer), que são questões de "alcova" e que, trazidas para a análise, constituem-se questões transferenciais cujo tratamento também estará restrito à palavra, embora dela escape em parte.

A atitude crítica de Freud (1896/1989e) com respeito ao desprezo teórico de Charcot para as questões da sexualidade evidencia a importância dada pelo criador da psicanálise à sexualidade, suas condições e manifestações, para o entendimento da constituição da subjetividade e do sujeito, na determinação de seu caráter ou personalidade.
Importância da sexualidade na determinação da singularidade de cada sujeito. O divã da hipnose e, em seguida, o divã da associação livre, reservam a vivência sexual às fantasias. Mas, diga-se ou reprise-se, as fantasias inconscientes carregam as marcas mais primitivas, características do processo primário (da representação-coisa e, não somente as marcas do representante da representação que supõe um trabalho terciário) — isto é, corpo e sexualidade se imprimem no inconsciente.

Se a psicanálise não é uma sexologia e, menos ainda, uma terapia sexual, precisamos entender que seu modo de lidar com as exigências sexuais-corporais passa pelo acolhimento, pelo suporte e pela continência dos processos ditos primários. Assim, tanto se pode pensar na consideração da fantasmagoria perversa a que sugere Aulagnier-Spairani (2003), que não deixa de conter uma certa ideia de perversão organizada (Meyer, 2013) - embora esta construída a partir de outras perspectiva que não as sugeridas por AulagnierSpairani -, como também se pode pensar na presença das expressões mimo-gesto-tônico-posturais que podem (ou não) acompanhar as narrativas em análise (Roussillon, 2012) - a se considerá-las originárias de exigências pulsionais, ainda que expressas na intersubjetividade do tratamento.

Também as concepções, veiculadas por Meyer (2013), da reprodução das experiências primarias de trauma nas manifestações perversas, precisam ser levadas em consideração, pois se aproximam das primeiríssimas compreensões freudianas - em alguma medida, nunca completamente abandonadas - da concretude do trauma, da vivência sexual primitiva que deixa traços antes de serem alcançadas pela simbolização que as palavras contêm.

\section{PARA TERMINAR: UMA PALAVRA SOBRE A SIMBOLIZAÇÃO, TRABALHO INCANSÁVEL DO PSIQUISMO}

Convém distinguir a simples presença da representação sem que necessariamente se dê ou se configure um estado de simbolização. Os vínculos entre representações são o que trazem uma perspectiva de sentido, como, por exemplo (já sabemos que o exemplo é a coisa mesma), as relações que se estabelecem entre representações nos dois momentos do trauma. A relação estabelecida em posterioridade, como a responsável pelo trauma, parece ser a matriz de toda constituição simbólica. Green (2001) sugere também a ideia da necessária relação em posterioridade para constituir-se simbolizações que permitam a livre circulação dos investimentos pelas representações. A simbolização depende de relações significantes que se dobram sobre si mesmas. Em termos freudianos, distinguir as representações de coisas das representações de palavras e de objetos; mas também, pois que se trata de um campo bastante fluido esse das representações, as representações das representações representativas como distinções que reafirmam o trabalho de simbolização. 
As primitivas representações ou traços da vivência da satisfação (ou da dor) que conduzem à alucinação (portanto ativação da percepção) da satisfação pulsional na reativação da excitação de órgão, reafirmam nosso entendimento da inseparabilidade do sexual, do corporal e do psíquico - ao formato de três instâncias ou três dimensões de considerações da psicanálise, a serem consideradas teórica e analiticamente, que não se sobrepõem completamente e que também são impossíveis de se reduzirem umas a outra, sem que se perca o fundamento da constituição dos sujeitos.

Mantivemo-nos, neste estudo, restritos às relações ditas "internas", entre, para resumir, representações e vivências, para apontar os limites do psiquismo e salientar a importância na psicanálise do corpo e da sexualidade não simbolizáveis. Embora tenhamos apontado, com Green
(2000), a importância do objeto na constituição da cadeia pulsional, não desenvolvemos esse proeminente aspecto pelo motivo de uma delimitação intencional de nosso campo aqui. $\mathrm{O}$ que restou sem abordagem na apreensão da simbolização e que pode abrir para outras reflexões, é a dependência da simbolização à presença do outro (em suas várias formas e de efeitos distintos sobre os processos de subjetivação). Segundo uma compreensão sugerida por Kristeva (2000), a importância do outro para a simbolização no desenvolvimento freudiano, aparece diante da tendência ao fechamento narcísico e se imporia como preocupação com o incremento da teoria pulsional com a pulsão de morte. Mas isso se constitui assunto vastíssimo que merece uma outra abordagem.

\section{REFERÊNCIAS}

Aulagnier, P. (1994). Los destinos del prazer: Alienación, amor, paisón (I. Mazi, Trad.). Paidós.

Aulagnier-Spairani, P. (2003). A perversão como estrutura. Revista Latinoamericana de Psicopatologia Fundamental, 6(3), 43-69. https://doi.org/10.1590/1415-47142003003004

Birman, J. (1996). A economia do gozo e os impasses da justiça: Uma leitura psicanalítica da justiça. Physis, 6(1-2), 121-134. https://doi.org/10.1590/S0103-73311996000100006

Celes, L. A. M. (1995) Sexualidade e subjetivação: um estudo do Caso Dora. Brasília: Ed. UnB.

Delouya, D. (2001). Dor, mais. Percurso - Revista de Psicanálise, 14(27), 77-83. http://revistapercurso.uol.com.br/pdfs/ p27_texto08.pdf

Fairbairn, W. R. D. (1980). Estudos psicanalíticos da personalidade. Interamericana. (Texto originalmente publicado em 1952)

Ferenczi, S. (1992). Confusão de língua entre os adultos e a criança (A linguagem da ternura e da paixão). In Obras completas Psicanálise IV (Á. Cabral, Trad. Vol. IV, pp. 97-106). Martins Fontes. (Texto original publicado em 1932)

Freud, S. (1987). La interpretación de los sueños. In J. Strachey (Ed.), Sigmund Freud. Obras completas (J. L. Etcheverry, Trad., Vols. 4 e 5, pp. 1-611) Amorrortu. (Texto original publicado em 1900)

Freud, S. (1988a). Fetichismo. In J. Strachey (Ed.), Sigmund Freud. Obras completas (J. L. Etcheverry, Trad., Vol. 21, pp. 141-152). Amorrortu. (Texto original publicado em 1927)

Freud, S. (1988b). Proyecto de psicología. In J. Strachey (Ed.), Sigmund Freud. Obras completas. (J. L. Etcheverry, Trad., Vol. 1, pp. 323-446). Buenos Aires: Amorrortu. (Texto original publicado em 1950)

Freud, S. (1989a). Fragmento de análisis de un caso de histeria. In J. Strachey (Ed.), Sigmund Freud. Obras completas (J. L. Etcheverry, Trad., Vol. 7, pp. 1-108). Amorrortu. (Texto original publicado em 1905)

Freud, S. (1989b). Tres ensayos de teoría sexual. In J. Strachey (Ed.), Sigmund Freud. Obras completas (J. L. Etcheverry, Trad., Vol. 7, pp. 109-224). Amorrortu. (Texto originalmente publicado em 1905)

Freud, S. (1989c). El problema económico del masoquismo. In J. Strachey (Ed.), Sigmund Freud. Obras completas (J. L.
Etcheverry, Trad., Vol. 19, pp. 161-176). Amorrortu. (Texto original publicado em 1924)

Freud, S. (1989d). Pulsiones y destinos de pulsión. In J. Strachey (Ed.), Sigmund Freud. Obras completas (J. L. Etcheverry, Trad., Vol. 14, pp. 105-134). Amorrortu. (Texto original publicado em 1915)

Freud, S. (1989e). La herencia y la etiología de las neurosis. In J. Strachey (Ed.), Sigmund Freud. Obras completas (J. L. Etcheverry, Trad., Vol. 3, pp. 139-156.). Amorrortu.

Freud, S., \& Breuer, J. (1987). Estudios sobre la histeria. In J. Strachey (Ed.), Sigmund Freud. Obras completas (J. L. Etcheverry, Trad., Vol. 2). Amorrortu. (Texto original publicado em 1895)

Green, A. (2000). As cadeias de Eros - Actualidade do sexual. CLIMEPSI.

Green, A. (2001). A posição fóbica central. Psicanálise - Revista da Sociedade Brasileira de Psicanálise de Porto Alegre, 3(1), 3570. http://sbpdepa.org.br/site/wp-content/uploads/2017/03/APosição-Fóbica-Central.pdf

Kristeva, J. (2000). “As metamorfoses da "linguagem” na descoberta freudiana (Os modelos freudianos da linguagem). In Sentido e contra-senso da revolta. Poderes e limites da psicanálise I (pp. 62-112). Rocco.

Lindenmeyer, C. (2019) Les embarras du féminin. Paris: Ed. PUF.

Masson, J. M., (Ed.) (1986). A correspondência completa de Sigmund Freud para Wilhelm Fliess - 1887-1904. Imago.

Meyer, J. (2013). O desenvolvimento e a função organizadora da perversão: O exemplo do travestismo. Livro anual de psicanálise. (International Journal of Psycho-Analysis), 27(2), 291-310.

Roussillon, R. (2012). As condições da exploração psicanalítica das problemáticas narcísico-identitárias. Alter. Revista de Estudos Psicanaliticos, 30(1), 7-32. https://www.spbsb.org.br/site/ images/Novo_Alter/2012_1/01Roussillon.pdf

Vergote, A. (1970). Psychanalyse et anthropologie philosophique. In W. Huber, H. Piron, \& A. Vergote (Eds.), La psychanalyse, science de l'homme (3a ed., pp. 146-256). Charles Dessart.

Winnicott, D. W. (1945/1978). Desenvolvimento emocional primitivo. In Textos selecionados: Da pediatria a psicanálise (J. Russo, Trad., pp. 269-285). Francisco Alves. 